\title{
Retrospective evaluation of indications and birth results of cesarean section due to ophthalmologic diseases
}

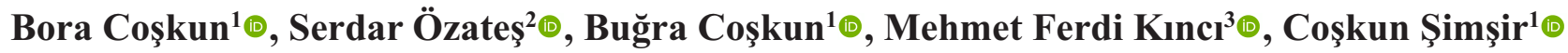

${ }^{1}$ Department of Obstetrics and Gynecology, Liv Ankara Hospital, Ankara, Turkey

${ }^{2}$ Department of Ophthalmology, Kars State Hospital, Kars, Turkey

${ }^{3}$ Department of Obstetrics and Gynecology, Muğla Sitkı Koçman Training and Research Hospital, Muğla, Turkey

\begin{abstract}
Objectives: To investigate the outcomes of cesarean section due to ophthalmologic indications.

Methods: This retrospective clinical study included 40,190 patients underwent cesarean section due to ophthalmological indications between January 2013 - August 2015 in MLP Care Group Hospitals (It includes 32 hospitals). Demographic data, ophthalmologic history and indications and surgical outcomes of caesarean section was assessed.

Results: Of the 53 patients with caesarean delivery due to ophthalmologic indications, $32(60.4 \%)$ had high degree myopia, 7 (13.2\%) had degenerative myopia, 8 (15.1\%) had history of ocular surgery, $2(3.8 \%)$ had history of vitreoretinal surgery due to retinal detachment, $2(3.8 \%)$ had glaucoma with uncontrolled intraocular pressure, $1(1.9 \%)$ had retinitis pigmentosa and $1(1.9 \%)$ had optic neuritis.

Conclusions: Ratio of ophthalmic indications is small within all cesarean indications and further longitudinal studies are needed to prevent from unnecessary cesarean section.

Keywords: cesarean section, myopia, retinal detachment
\end{abstract}

$\mathbf{N}$ umber of birth deliveries with cesareansection is rapidly increasing globally and in Turkey. Based on the data of the World Health Organization, number of deliveries with cesarean section had increased by 48.9\% between the years 1992 and 2007 [1]. Likewise, while the rate of births with cesarean section was $21 \%$ in Turkey in 2002, it increased to $47 \%$ in 2011 [2]. This means that 750,000 births with cesarean section occurs in the average each year in our country [3]. Although the reasons for preferring birth with cesarean section are commonly obstetric reasons such as repeat sections or fetal distress, the need for cesarean section can also arise with non-obstetric reasons [4]. Puzio et al. [5] have reported that $17 \%$ of cesarean section indications are related to non-obstetric reasons and $20.5 \%$ of non-obstetric reasons are ophthalmologic diseases.

Together with the several physiologic and pathologic effects of pregnancy on the eye, it can cause the deterioration of the course of existing ophthalmologic diseases [6]. It has been reported in the literature that diseases capable of leading to serious ocular morbidity including retinal detachment, central serous chorioretinopathy, pregnancy-related hypertensive retinopathy, papilledema, obstructions of retinal artery and vein and diabetic retinopathy can occur during pregnancy or their courses can deteriorate. In their study on 4895 pregnant women, Socha et al. [7] reported that $2.04 \%$ of indications of cesarean sections performed were ocular diseases. Furthermore, it has been stated that ocular diseases that are the most common cesarean indications are myopia, retinopathy and 
glaucoma [7].

Review of the literature shows that there is no consensus on planning the mode of delivery based on ocular diseases $[6,8,9]$. Furthermore, although this is an inter-disciplinary issue, number of studies that ophthalmologists and obstetricians work together on this issue is rather small. In our study, we aimed at evaluation of the effects of ophthalmologic diseases on the decision for the delivery mode in Turkey, and to carry out an inter-disciplinary evaluation.

\section{METHODS}

Pregnant women who delivered their babies with elective cesarean section in MLP Care Group Hospitals (It includes 32 hospitals) with indications related to ophthalmologic diseases between January 2013 and August 2015 were included in this retrospective study. The study was carried out after obtaining the approval of the ethical committee of MLP Care Group Hospitals (It includes 32 hospitals), Ankara (Number:2019/002).

Pre- and post-delivery ophthalmologic findings of all the pregnant women, for whom elective cesarean section was performed with ophthalmologic indications, were investigated from the records of their examination and ocular pathologies creating cesarean indication were recorded. Age, weight, length and body mass index (BMI) were noted. Gestational age, birth weight of the newborns were also noted. All the data required for the study were collected from the patient files after the patients were discharged. Reliability of information was secured through crosswise checks on anesthesia, nursing and obstetric reports.

Full ophthalmologic examinations were carried out on all the patients before the procedure. Visual acuity was determined using the Snellen scale.
Intraocular pressure measurements were carried out with noncontact tonometry (CT-80 Tonometer, Topcon, Japan), and Goldmann applanation tonometry was used to repeat the managements for results exceeding $21 \mathrm{mmHg}$. Macula, optic disk and peripheral retinal examination was carried out with the help of Goldmann 3-mirror lens after dilation of the pupils and topical anesthesia. Optic coherence tomography and fundal fluorescence angiography were performed if needed. Patients with high myopia, degenerative myopia, history of retinal detachment, history of ocular surgery, retinitis pigmentosa and history of optic neuritis did not receive any treatment unless there was an associated complication. Only patients with glaucoma attended scheduled control visits before and after cesarean section for medical management.

\section{Statistical Analysis}

Statistical Package for the Social Science (SPSS Version 22.0, Armonk, NY: IBM Corp) software were used to analyze the study outcomes. The normal distribution assumption of the data was tested by the Shapiro-Wilk test. Frequencies of the variables were calculated. A $p$ value $<0.05$ was considered as significant.

\section{RESULTS}

Fifty-three pregnant women that gave birth with cesarean section because of ocular diseases out of 40,190 that gave birth with cesarean section between the above mentioned dates were included in the study. Rate of pregnant women, for whom cesarean section was performed because of ocular diseases was calculated as $0.13 \%$. In this study, the mean age was $26.75 \pm 5.08$ years and the mean BMI was $29.75 \pm$ $5.08 \mathrm{~kg} / \mathrm{m}^{2}$. Demographic characteristics of patients

Table 1. Demographic data of the patients

\begin{tabular}{lcccc}
\hline & Minimum & Maximum & Mean & Std. Deviation \\
\hline Age (years) & 18 & 38 & 26.75 & 5.08 \\
Length $(\mathrm{cm})$ & 145 & 185 & 161.96 & 6.55 \\
Weight $(\mathrm{kg})$ & 55 & 112 & 77.32 & 13.30 \\
BMI $\left(\mathrm{kg} / \mathrm{m}^{2}\right)$ & 20.2 & 44.2 & 29.75 & 5.51 \\
\hline
\end{tabular}


Table 2. Distribution of indications based on ocular diseases in patients, for whom cesarean section was performed

\begin{tabular}{lcc}
\hline & $\begin{array}{c}\text { Ophthalmic Disorders } \\
(\mathbf{n}=\mathbf{5 3})\end{array}$ & $\begin{array}{c}\text { Cesarean indications } \\
(\mathbf{n}=\mathbf{4 0 , 1 9 0})\end{array}$ \\
\hline High Myopia $(\mathrm{n}=32)$ & $60.4 \%$ & $0.079 \%$ \\
Degenerative Myopia $(\mathrm{n}=7)$ & $13.2 \%$ & $0.017 \%$ \\
Retinal Detachment $(\mathrm{n}=2)$ & $3.8 \%$ & $0.004 \%$ \\
Previous Ocular Surgery $(\mathrm{n}=8)$ & $15.1 \%$ & $0.019 \%$ \\
Uncontrolled Glaucoma $(\mathrm{n}=2)$ & $3.8 \%$ & $0.004 \%$ \\
Retinitis Pigmentosa $(\mathrm{n}=1)$ & $1.9 \%$ & $0.002 \%$ \\
Optic Neuritis $(\mathrm{n}=1)$ & $1.9 \%$ & $0.002 \%$ \\
\hline
\end{tabular}

are given in Table 1.

Gestational diabetes was found in $1(1.9 \%)$ of the patients, who participated in the study, hypertension accompanying gestational diabetes in $1(1.9 \%)$, type 2 diabetes mellitus in $1(1.9 \%)$, pregnancy cholestasis was found in $1(1.9 \%)$ and epilepsy was found in 1 $(1.9 \%)$ of the patients who participated in the study. However, lack of any effects of pregnancy on these diseases was confirmed by the ophthalmologist.

Of the 53 pregnant women, for whom cesarean section was performed because of ophthalmic disorders, 32 (60.4\%) had high myopia, 7 (13.2\%) had degenerative myopia, $2(3.8 \%)$ had past retinal detachment, 8 (15.1\%) had past ocular operations, 2 (3.8\%) had uncontrolled glaucoma, 1 (1.9\%) had retinitis pigmentosa and 1 (1.9\%) had optic neuritis. No changes were observed in their findings related to their respective ophthalmologic disease in the examination carried out at month 1 following delivery. No ocular complication associated with cesarean section was observed 1 moth after the cesarean section.

Of the 52 newborns who were given birth through cesarean section, mean birth weight was 3,281 \pm 438 grams, gestational age was $38.3 \pm 0.7$ weeks and mean RDS was observed in $2(3.8 \%)$, wet lung and hypoglycemia in $1(1.9 \%)$, patent foremen ovale in 1 (1.9) and neonatal icterus was observed in 1 (1.9\%).

\section{DISCUSSION}

There is no consensus between obstetricians or between ophthalmologists as regards whether or not ophthalmologic diseases are indications for cesarean section. Chiu et al. [8] have reported that $34 \%$ of obstetricians recommend delivery with cesarean section in pregnant women with retinal detachment risk, while $4 \%$ of ophthalmologists recommend it for the same condition. Recommendation of cesarean section by $26 \%$ of ophthalmologist in the same study in pregnant women who had been treated because of retinal detachment while Inglesby et al. [10] had stated that past retinal detachment surgery is a contraindication for vaginal delivery shows that there is no consensus in this issue even between ophthalmologists, cesarean section was performed on only 2 patients because of retinal detachment. Furthermore, we are unable to carry out a statistical comparison with the reason that there were not patients with retinal detachment who had vaginal delivery. This is the most important limitation of our study.

In their study on 4,895 pregnant women, Socha et al. [7] reported that $2.04 \%$ of cesarean section indications were ocular diseases. This ratio was calculated as $0.13 \%$ in our study. We consider this ratio somehow too small based on the fact that cesarean section rates with obstetric causes are rather high in our country. However, statements based on net numbers require larger studies. It was stated in the same study that ocular diseases constituting the most frequent cesarean indications include myopia, retinopathy and glaucoma. These results are similar with ours.

Psenkova et al. [11] showed that number cesarean 
operations with non-obstetric indications significantly reduced after training of obstetricians on non-obstetric cesarean section indications. These data reported in the literature indicate that more studies are required on the issue of how the ophthalmologic diseases affect the mode of delivery, and training on this issue is required for the relevant specialty areas.

It is thought that the acute increase in intraocular pressure and decrease in ocular perfusion related to the valsalva maneuver during vaginal delivery can cause optic nerve damage in glaucoma patients [12]. Cesarean section is recommended for patients with high grades of myopia or retinal degeneration based on the thought that vaginal delivery can trigger retinal detachment $[13,14]$. In the studies of Sochaet al. and in our study, the most frequent cesarean indications are myopia and retinaldetachment. However, there are no evident-based reports in the literature indicating that vaginal delivery is associated with retinal detachment or progression of glaucoma [13, 14]. Animal experiments, observational and comparative studies covering the pre- and post-delivery periods in pregnant individuals with ophthalmologic diseases are required.

To our knowledge, neither a gynecologist, nor an ophthalmologist can decide cesarean section due to an ophthalmologic indication. Mohammadi et al. [15] emphasized that all gynecologist expressed the need of ophthalmologist's suggestion for cesarean section due to ophthalmologic indications. There is no guideline in management of pregnant patients with ocular disorders; therefore, it should be a mutual decision of both gynecologists and ophthalmologists as it was in the present study.

\section{CONCLUSION}

In conclusion, ophthalmologic concerns direct both gynecologists and ophthalmologists to cesarean section. Although ratio of ophthalmic indications is small within all cesarean indications, further longitudinal studies are needed to prevent from unnecessary cesarean section.

\section{Conflict of interest}

The authors disclosed no conflict of interest during the preparation or publication of this manuscript.

\section{Financing}

The authors disclosed that they did not receive any grant during conduction or writing of this study.

\section{REFERENCES}

[1] Declercq E, Young R, Cabral H, Ecker J. Is a rising cesarean delivery rate inevitable? Trends in industrialized countries, 1987 to 2007. Birth 2011;38:99-104.

[2] Erol H, Özdemir A. [Health reforms and the evaluation of health expenditures in Turkey]. Sosyal Güvenlik Dergisi 2014,4:9-34. [Article in Turkish]

[3] Ulubay M, Öztürk M, Fidan U, Keskin U, Firatlıgil FB, Kınc1 $\mathrm{MF}$, et al. Skin incision lengths in caesarean section. Cukurova Med J 2016,41:82-6.

[4] Festin MR, Laopaiboon M, Pattanittum P, Ewens MR, Henderson-Smart DJ, Crowther CA; SEA-ORCHID Study Group. Caesarean section in four South East Asian countries: reasons for, rates, associated care practices and health outcomes. BMC Pregnancy Childbirth 2009,9:17.

[5] Puzio M, Szczurowicz A, Rogoza A, Zwaliński M. [Nonobstetric indications for cesarean section from five years of material]. Ginekol Pol 1996,67:383-6. [Article in Polish]

[6] Taner P, Akarsu C. [Ophthalmic changes in pregnancy]. J RetVit 2001,9:169-78. [Article in Turkish]

[7] Socha MW, Piotrowiak I, Jagielska I, Kazdepka-Ziemińska A, Szymański M, Duczmal M, et al. [Retrospective analysis of ocular disorders and frequency of cesarean sections for ocular indications in 2000-2008 -- our own experience]. Ginekol Pol 2010;81:188-91. [Article in Polish]

[8] Chiu H, Steele D, McAlister C, Lam WC. Delivery recommendations for pregnant females with risk factors for rhegmatogenous retinal detachment. Can J Ophthalmol 2015;50:11-8.

[9] Loncarek K, Petrovic O, Brajac I. Myopia and operative delivery in Croatia. Int J Gynaecol Obstet 2004;85:287-8.

[10] Inglesby DV, Little BC, Chignell AH. Surgery for detachment of the retina should not affect a normal delivery. BMJ 1990;300:980.

[11] Psenkova P, Bucko M, Braticak M, Baneszova R, Zahumensky J. Impact of introducing specific measures to reduce the frequency of cesarean delivery for non-obstetric indications. Int J Gynaecol Obstet 2018;142:23-7.

[12] Mackensen F, Paulus WE, Max R, Ness T. Ocular changes during pregnancy. Dtsch Arztebl Int 2014;111:567-76.

[13] Landau D, Seelenfreund MH, Tadmor O, Silverstone BZ, Diamant Y. The effect of normal childbirth on eyes with abnormalities predisposing to rhegmatogenous retinal detachment. Graefes Arch Clin Exp Ophthalmol 1995;233:598600.

[14] Jünemann AG, Sterk N, Rejdak R. [Influence of mode of delivery on pre-existing eye diseases]. Ophthalmologe 2012;109:229-34. [Article in German]

[15] Mohammadi SF, Letafat-Nejad M, Ashrafi E, DelshadAghdam H. A survey of ophthalmologists and gynecologists 
regarding termination of pregnancy and choice of delivery mode in the presence of eye diseases. J Curr Ophthalmol 2017;29:12632. 